\title{
TRAVMATIK BIR YAŞANTI: MEME KANSERI VE MASTEKTOMi
}

\author{
Ruşen Nur ARIKAN*
}

\section{ÓZET}

Son yillarda kanserın tanı ve tedavısınde onemlı gelışmeler olmasına rağmen, hâlâ olumcul bır hastalık olma ozelığını korumaktadır. Kanser turlerı ıçerısınde kadınlarda en sık gorulen meme kanserı, kanser olmanın verdığı korku ve kaygının yanında, kadının kımlığı ıçın buyuk onem taşıyan "meme"nın de kaybına yol açmaktadır Meme kanserı nedenıle mastektomı uygulanan hastalar, kanser ve cerrahı gırışımle ı|gil psikososyal zorlanmalar yaşarlar Mastektomı kadının benlık ımaıını, crnsel yaşamını ve alle ıışkılerın। olumsuz yonde etkılemektedır Hasta ve aılesının korkuları, kaygıları, çatışmaları ve kanserle ılgıiı çeşttlı donemlerdekı krızlerıyle başetmelerıne, Lıyezon psıkıyatrısı ve Onkolojı arasındakı yakın ışbırlığının onemlı katkıları olacaktır

Anahtar Kelimeler: Meme kanserı, mastektom, psıkolojk problemler, psikoseksuel uyum, hasta ve allesı

- Uz Psk AUTF Ibnı Sina Hastanesı Psıkıyatrı Konsultasyon Liyezon Unitesı
Travmatic An Experience:

Breast Cancer And Mastectomy

\section{SUMMARY}

Although there are great developing in the dagnosis and treatment of cancer recently, it is still a lethal disease Breast cancer which is the most seen in cancer women causes lost of bre. ast that has important meaning in woman IIfe, in addition to worry of being cancer Pateınts with breast cancer who undergo the mastectomy worry because of being cancer and having a surgical operation Mastectomy effects the woman's personality, sexuel life and tamıly relatıonship badly Patient and her family's fears, worres, arguments and crisis because of being cancer can be solved by cooperation between Oncology and Lıason psychıatry

Key words: Breast cancer, mastectomy, psychological problems, psychosexual adaptatıon, patıent and her family. 


\section{GRợ}

Yaşamın herhangı bır noktasında hepımız bır krızle karşı karşıya kalabılııı Olumcul bır hastalık olarak bılınen "kanser", kışıyı boyle bır krız donemının ardindan bırçok varoluş sorunlarıyla yuzyuze getirmektedır Son yillarda kanserm tant ve tedavisınde onemlı geiışmeler olmasına rağmen tedavisının uzun ve pahalı olması, organ kaybına yol açabılmesi, hastalığın yayılabılır ofmaș। ve kımı zaman olumle sonuçlanabılmesı hasta ve yakın çevresıne ağır psıkososyal problemlerı de beraberınde getırmektedır

Kanserlı hastanın ruhsal yonden etkıłenışı hastanın benlık gucu, kışılık yapısı, kanserlı organına verdığı değer, alle duzenı, meslek ve parasal durumu, destekleyıcı uğraşıların olup olmaması gıbı bırçok değışkenlere bağlıdır Kanserın ruhşal yaşam uzerındekı etkılerı ve hasta hekım ilsșklerı açısından gerek cerrahlar, gerekse ruh hekımlerınce yapılan yayınlarda kışının hasta organına verdığı değer ve anlamın onemli yerı olduğu belırtılmektedır Orneğın memesını butun kadınlığı ıle eşdeğer tutan bır kadının meme kanserıne tepkısı de o oranda ağır olabılır (Ozturk 1978)

Kanser turlerı ıçerısınde kadınlarda en sık gorulen meme kanserı, kanser olmanın verdığı korku ve kaygının yanında, kadının kımılı̆ı ıçın buyuk onem taşıyan "meme"nın de kaybına yol açmaktadır

1995 yılı rakamlarına gore A BD'de kanser hastası kadınların \%31 7'sını meme kanserlı kadınlar oluşturmaktadır Turkıye genelınde ıse yine 1995 yılı rakamlarına gore ık 5 sırayı alan kanser olgularmın başında \%149 tle meme kanserı bırıncı sırayı almaktadir (Fırat ve Celık, 1998)

Meme kanseri memellerden sadece insan ve farede gorulen genlerle ılıskılı bır hastalıktır Genel belırtı memede şışıktır 25 yaş cıvarında başlar ve yaş ılerledıkçe artar Tanı bıopsı ıle konur tedavı hastalığın evresıne gore yapılır
Bazı amelıyat edılemez durumlar vardır Orneğın, lenf nodu metastazlart (yaylıma), uzak metastazlar, yaygin odem varsa hasta amelyyat edılemez Boyle durumlarda hastaya kemoterapı (Ilaç tedavis) veya radyoterapı (radyoaktı ışın tedavısı) uygulanır Eğer hastanın bu tur engeilerı yoksa, hastanın memesı alınma yoluna gidılır $\mathrm{Bu}$ cerrahı ışleme "mastektomı" denır Mastektomı sonrasında da hastaya onleyıc tedavı olarak kemoterapı uygulanabılır Radıkal mastektomıde 10 yıllık yaşam \%78'dır Amelıyat sonrası metastaz olabilir Metastaz en sik ilk 2 yıl içınde olur, ancak, lerıkı yıllarda da ortaya çıkabılır (Bazlı ve Unal, 1988)

\section{MEME KANSERINE PSIKOLOJIK TEPKILER}

Kanser ınsan yaşamını çeşıtlı yonlerıyle etkllemekte ve kanser olan kışı çeşıtlı donemlerden geçmektedır Kubler-Ross (Akt Ozkan ve Turgay 1995) bu donemlerı şoyle siralamıştır

1 inkar ve izolasyon

2 Ofke

\section{Pazarilk}

\section{Depresyon}

\section{Kabullenme}

Kanser hastalarında gorulen başa çıkma tepkılerınden en çok alıı çızılen ınkardır Burada kullanılan ınkarın dınamığı psıkanalıtık lıteraturde kullanilandan farktıdır Hacett ve Cassem (AKt Ozkan ve Turgay 1995)'ın ınkar tanımı, kansere karşı gelıştırılen uyum mekanızmasında ortaya çıkan ınkarı en ıyı tanımlamaktadır "Kışının daha az psışık stres altında ışlev gormesı ıçın, tehdıtkar bır gerçek parçasının etkısının azaltılma"dır Yalom (1995) "Ozel olduğumuza ınanmak ıçten ıçe bıt guvenlık duygusu saḡlar" der Ozel olma'yi, "Bır kımsenın insan blyolojısıntn olağan yasajarının ve yargısının otesınde, dokunulmaz ve incıtılemez olduğu ınancıdır" dıye tanımlar Kanser tanısı alan kışı de sık sık "Bu gerçek olamaz", "Ben kanser olmam" gıbı cum- 
lelerle inkarını dıle getırır Inkar mekanızmasının bozulması hastanın depresyona gırmesıne neden olur Anksıyete, kızgınlık, keder, ağrı, yemek yememe ve uykusuzłuk da ortaya çıkabılır (Polivy 1975)

Meme kanser nedeniyle mastektomı uygulanan hastalar kanser ve cerrahı gırı̧̧ıle ıgılt endışe ve zorlanmalar yaşarlar Bu psikososyal zorlanmaları Ozkan ve Turgay (1995) Tablo l'de şoyle ozetlemışlerdır

\section{MASTEKTOMI VE BEDEN IMAJI}

Butun kanser turlerı ıçerısınde psıkolojık faktorier bakımindan, meme kanserı lle Ilgılı yayın ve araştırmaların daha fazla olduğu dıkkat çekmektedır Meme bırçok yerleşık duygusal ve kulturel unsurlar taşımaktadır. Gyllenskold (Akt. Ure, 1983) memenın kadınlar açısından taşıdığı onemı şoyle belırtır

- Memeler kadının kadınlığını ve cazıbesını gosteren organlardır

- Memeler annelığın, beslenme ve uremenın semboludur

- Memeler ozeilkkle kadına ozgu sut ve hayat vericı organlardır

- Memeler cinsel ilışkide onemlı ve cınsel duyarlığı olan organlardır

Memenın aiınmasına gosterılen psıkolojık tepkılerın derecesı, kadının memesıne ılışkın algısıyla yakından ılgılıdır Insan kışılığının geIş̧ımınde beden ımajı algısı onemlı bır ışleve sahıptr vucut organ ve dokularının psıkolojık sembolłk anlamları vardır Cınsel kımlığın geIsşmesınde beden ımaıının algılanma şeklı ve atfedılen değerler onemlıdır Beden imaıı norolojık hastalıklarda bozulabıldığı gıbt, vucut organlatinin amputasyonu lie de değışıklığe uğrayabılır Psıkolojık açıdan beden ımajı ınsanın kendı bedenınden ne olçude hoşnut ve memnun olduğunu fade eder Fizıksel gorunum de- ğışımlerınden sonra vucut ımajı değışıklıklerı bu fızıksel değışımlerın kışı ıçın oznel nıtelık ve anlamına, bu değışıklıklerın kışı tarafından nasıl algılandığına, kışının kışııı yapısı ve çevre etkılerı gıbı psıkolojk, bilışsel ve sosyal faktorlere gore şekılienır (Ozkan ve Turgay 1995)

\section{MASTEKTOMIDE GORÜLEN RUHSAL BOZUKLUKLAR}

Kanserlı hastalarda ruhsal bozuklukların ozelıklerını ve yaygınlığını araştırmada bazı guçlukler vardır Orneğın; bır bulgunun ne oranda fizıksel, ne oranda ruhsal kokenli olduğunu ayırtedebılmek çoğu zaman guçtur (Adams, 1988). Standart olçutlerın yaygın olarak kuilanılmaması ve oldukça farklı araştırma yontemlerııın kullanılması ıse araştırma sonuçlarının karşılaştırıımasını engellemektedır (Massıe ve Holand 1988, Silberforb ve Oxman 1988)

Bazı kanser tıplerının daha fazla ruhsal sorunlara yol açtığı, orneğın, mastektomı sonrası, ozellıkle de kemoterapı eklenırse psikıyatrık bozukluk oranının artığı bıldırımıştır (Hardman ve ark 1989)

Clifford (1979), mastektomı yașantısının amelyat oncesinde ve sonrasında farklı tepkilere neden olduğunu soylemektedir Ameliyat oncesı sorunlar kaygı ve lietışım problemlerı uzerınde yoğunlaşmakta, amelıyat sonrasında tse has. tanın beniık tasarımı, beden ımajı, hastalıkla ılgılı korku ve endışe duygularına ıIışkın sorunları ortaya çımmaktadır. Kisa surelı olumsuz etkıler cınsel ilışkıde, evliıkte, sosyal ve kışıerarası lışkılerde gorulmektedır Daha uzun vadede protez ve kıyafete Ilşkın sorunlar gundeme gelmektedır

Kanser hastalarında ruhsal bozukiuklar, ozellıkle depresyon gorulme sıklığı bırçok araştırmaya konu olmuş ve $\% 45-\% 58$ arasında değışen depresyon oranlan bıldırımıştır (Massie ve Holland 1988) Cassileth ve Steinfeld (1987) mastektomıden sonra bazı kadınların depresyona gırdıklermı ya da kızgınlık tepkısı ge- 
Tablo I: Meme kanserı olan kadınların tanı ve tedavı surecınde gosterdıklerı psıkolojık tepkıler

\begin{tabular}{|c|c|c|}
\hline & Normal (Adaptrf) & Maladaptif \\
\hline Tanı Onesı & 1 Kanser olasıliı̆ı ıle ılgılı kaygıilı bekleyış & $\begin{array}{l}1 \text { Kanser tanısı konmadan } \\
\text { hastalık belırtlerı gelıştırme }\end{array}$ \\
\hline Tanı Aşaması & 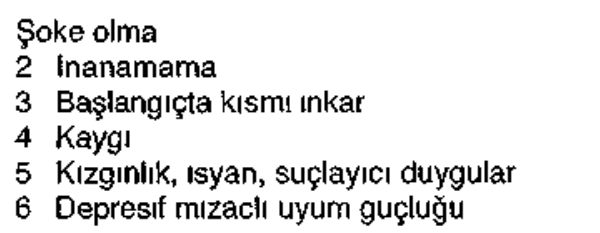 & $\begin{array}{l}\text { Kesın inkar tedaviy| reddetme } \\
2 \text { Olumun kaçınımaz olacağı } \\
\text { duşuncesı lle tedaviyı } \\
\text { reddetme }\end{array}$ \\
\hline Tedavı Aşaması & $\begin{array}{l}\text { Cerrahı Tedavı } \\
1 \text { Cerrahı gırışımın gecıktırıımesı } \\
2 \text { Cerrahı dışı tedavıler arayışı } \\
3 \text { Vucut ımajı değışıklğıne bağı kayıp } \\
\text { tepkısı } \\
\text { Radyoterapı } \\
1 \text { Işın tedavısının yan etkılerınden korkma } \\
2 \text { Terkedılme korkusu } \\
\text { Kemoterapı } \\
1 \text { Yan etkılerınden korkma } \\
2 \text { Vucut ımajı değışılklklerı } \\
3 \text { Kaygı, ızolasyon eğıımı hafıf depresıł } \\
\text { duygu durumu } \\
4 \text { Alturuıstık duygular } \\
\text { (Organlarını bağışlama) }\end{array}$ & $\begin{array}{l}1 \text { Amelıat sonrası reaktıf } \\
\text { depresyon } \\
2 \text { Vucut ımajı değısıklıkklerı ve } \\
\text { uzamış cıddı elem reaksıyon } \\
1 \text { llaca bağlı psıkotık rezıduel } \\
\text { bulgular } \\
2 \text { Jlerı ızolasyon ve } \\
\text { deprıvasyon hallerı psıkotık } \\
\text { inkar } \\
3 \text { Paranotd tepkıler }\end{array}$ \\
\hline Tedavı Aşaması & $\begin{array}{l}1 \text { Normal başetme duzeneklerıne ve } \\
\text { hastalık-tedavı sinıriarı lçınde yaşama } \\
\text { donuş } \\
2 \text { Nuks korkusu }\end{array}$ & \\
\hline Nuks & $\begin{array}{ll}1 & \text { Soke olma } \\
2 & \text { Inanamama } \\
3 & \text { Kısmı ınkar } \\
4 & \text { Kaygı } \\
5 & \text { KIzginlık } \\
6 & \text { Depresıf duygu durumu }\end{array}$ & $\begin{array}{l}1 \text { Uykusuzluk, ıştahsızlık } \\
\text { gıda reddı, huzursuzluk, } \\
\text { panık halı, katastrofık } \\
\text { algı, suçlayıcı duşunceler } \\
\text { le belıgın reaktı } \\
\text { depresyon }\end{array}$ \\
\hline Hastaliğın Seyır ve llerlemesı & $\begin{array}{l}1 \text { Yenı bilgı araştırma ve çeşttlt tedav } \\
\text { olastıklarına donuk arayış ve } \\
\text { konsultasyonlar }\end{array}$ & 1 (Major) Depresyon \\
\hline Termınal-Palyatif Donem & $\begin{array}{l}1 \text { Terkeditme korkusu, ağrı, bilınmezlık } \\
\text { korkusu, varoluşçu endişeler } \\
2 \text { Olum duşuncesıne bağlı kışısel elem } \\
\text { duygusu ve (umut korkusu) kabullenış }\end{array}$ & $\begin{array}{ll}1 & \text { Depresyon } \\
2 & \text { (Akut) Delirum }\end{array}$ \\
\hline
\end{tabular}


Iıştırdıklerını soylemışlerdır Kadının aıle ve arkadaşlarından gerı çekileceğın, duygusal gerıleme olacağını ve bazen de eşıne ve allesıne suçlamalarda bulunabıleceğını belırtmışlerdir. Dean ve Hopwood (1989) yayınlanan bir yazilarında, mastektomı sonrası gorulen ruhsal bozuklukların daha çok mınor duygulanım bozukluğu olduğunu belırtmışlerdır

Mastektomı olan hastalar, ameliyattan sonra kanserın vucutlarından tamamen çıkarılıp çıkarımadığı kanserın tekrar ortaya çıkacă̆ı, veya yayılacağı konusunda da endışe yaşarlar Hastalığın yayılması veya nuksetmesı hasta ıçın buyuk bır yıkımdır Ağrıların çok yoğun yaşandığı bu donemde hastada uyku ve ıştah bozuklukları, hareketlilkte azalma, depresyon ve anksiyete gorulur (Derogotıs ve ark 1979)

Yapilan çeşıtlı araştırmalarda mastektomı olan hastaların onemlı bir bolumunde ruhsal soruniarın bir yılı aşkın surelerde devam ettığıne ıışkın bulgulara rastlanmıştır Bu konuyla ılgılı olarak Hutchınson, Ferndon ve Wilson (1979) yaptikları bur araştırmada bır yı! once memesı alınmış hastaların \%39 unda yuksek duzeyde kaygı, çokkunluk ve cinsel problem olduğunu tespıt etmışlerdır Morrıs ve arkadaşları tarafından gerçekleştırılen başka bır çalışma (Akt. Hoqwood ve Maquire 1988), mastektomı yapılan kadınların ameliyattan 2 yıl sonra hala bu değışıklığe bağı seksuel problemlerı olduğunu ve duşuk kendılık değerı (self-esteem) duzeyınde oldukların gostermektedir Benzer bir sonuç Wolberg ve arkadaşlarının (1989) mastektomı olmuş 78 hastayla yaptıkları çalışmada da bulunmuştur Araştırmacılar psıkolojık sorunların amelıyattan sonra 16 aya kadar devam ettığını belırtmışlerdır

Yukarıda sozu edılen çalışmalar mastektom! sonrasında kadınlardakı ruhsal sorunların uzun sure devam ettığını gostermekle bırlıkte, dığer taraftan iteraturde yukarıda bahsedilen sonuçları desteklemeyen araştırmalara da rastlanmaktadır Bloom ve arkadaşları (1987), 1 yıllık Evre I ve II meme kanserlı hastaları, kolesıstektomı ameliyat: geçırmış ve selım meme hastalığı ıçın bıyopsı yapılan sağlıklı kadinlarla karşılaştırmışlardır Meme kanserlı grupta kışılerarası Ilışkılerde guçluk, somatik anksiyete ve kendını değersız butmanın dığer gruplardan daha yuksek değerlerde olduğu, ancak amelıyattan sonrakı 1 yli boyunca psıkıyatrı mudahale gerektırecek cıddi psıkopatolojk belıtıler gostermedıklerını bulmuşlardır Bu verler daha once psıkolojı olarak sağlıkı olan kadınlarda mastektomı sonrasında cıddı psıkıyatrık belırtılerın çıktığı ınancını desteklememektedir

\section{MASTEKTOMI VE CINSELLIK}

Meme kanserı ve mastektominın cınselttk ve beden ımâı uzerıne etkısıne ısşkın bırçok çalışma yapılmıştır Henuz ulkemızde yaygın olmamakla birlikte yurtdışında oldukça yaygın olarak uygulanan lumpektomının (goğsun korunarak amelıyat edılmesı) meme kansert olan kadınlardaki psıkolojık sorunları daha aza ındırdığı duşunulmektedır

Bu konuda bır çalışma yapan Meyer ve Aspergen (1988) radıkal mastektomı yapılmış bır grup hasta ile, goğsu korunarak ameliyat edılmış aynı zamanda radyoterapı alan bır grup hastayı 5 yıl boyunca incelemışlerdır Psiklyatrk bozukluk, evlığe uyum ve kanserın tekrarlama korkusu bakımından mastektomı olmuş kadınların \%30'u ve goğsu korunarak amelıyat edılmış kadınların $\% 29$ 'u benzer sonuçlar gostermışlerdır Fakat goğsun korunması, kadının dışlık kımlığını ve vucut goruntusunu kabullenmeyı kolaylaştırmıştır

Konuyla ıfgil dığer bir araştırma Wolberg ve ark (1989) tarafından yapıımıştır Bu çalışmada, mastektomı olan 78 hasta ve goğsu korunarak amelıyat edilmış 41 hasta karşılaştırılmış, ıkı grup arasında amelyyat sonrası uyumları, psikopatolojlerı ve seksuel problemlerı bakımından çok kuçuk farklar bulunmuştur Yanı psıkoloık sorunlar amelıyatla goğsun korunması lle ortadan kaldırılamamıştır 
Schover (1991), goğus kanserı kadınlarla ılgılı bir yazısında goğus kanserı teşhısınden sonra goğusu koruyarak amellyat etmenın veya protez takmanın sekssuel probiemierın ıylleştırılmesıne etkısının az olduğunu belırtmışıı.

Yapılan araştırmalarda goğsun korunarak amelıyat edılmesı kadının dışılık kımlığını ve vucut goruntusunu kabulienmeyı kolaylaştırdığı, ancak psıkolojık kaygı, psıkıyatrık bozukluk aıle uyum ve mutluluğu cınsel ıılşkı sıklığı ve cınsel uyum açısından total mastektomı ve parsıyel mastektomı grupları arasında anlamlı bır farklııı olmadığı gorulmektedır

Mastektomının kadının seksuei yaşantısı uzerinde de onemil etkilen vardir. Meyer ve Aspergen (1988) tarafindan yapilan bir araştırmada meme ameliyatı geçırmış kadınların \%24'u sekse karşı ılgılerının azaldığını, \%17'sı memenın ellenmesınden kaçınmak ve karanlıkta bırleşme gibı memelerıyle ılgıı cınsel alışkanlık değışımı olduğunu bildırmışlerdır.

Ameliyat sonrası plastik ve rekonstruktıf protez uygulamasının beden ımajı algısını olumlu etkıledığı belırtımıştır Ancak sadece protez uygulamasının kadının cınsel arzu, çekıcılık duyguları ve cınsel doyumunu artırdığını ıddia etmek guçtur Bu uygulama butunluk hissint arttirmaktadır Kadının butuncul ruhsal uyumu, ilş̧kılerindekı doyumu, hastalık oncesı cinsel yaşam ozelliklen, ameliyat sonrası cinsel uyum ve doyumda, memelerının ne kadarının alındığından daha çok etkılı olduğu gozukmektedır. Bazı yazarlar kemoterapı ve radyoterapının, cinsel ıstek uzerınde olumsuz etkısı olduğunu belırtmışlerdır (Ozkan ve Turgay 1995)

\section{KANSERLI HASTA VE AILESI}

Kanser sadece hastayı değıl onun en yakın çevresını, allesını ve arkadaşlarını da olumsuz şekılde etklemektedır Casslleth ve Stenneld (1987) memesı alınan kadının kocasına karşı kendını seksuel açıdan yetersız ve eksık hıssedıp ondan uzaklaşı̆̆ını, kocanın ıse çoğu kez eşının uzerıne gereğınden fazla duştuğunu, zaman zaman ıse eşının dışılık ozeliığını yıtırdığı endışesıyle cınsel yakınlaşmadan kaçtığını beIırtmektedirler

Northouse (1989), yaptığı bır çalışmada 50 tane mastektomı olmuş kadın ve onların eşlerıle goruşmuş ve bu goruşmelerı teybe almıştır Daha sonra bunları rapor ettığınde hem hastaların, hem de eşlerının oldukça yoğun endışelerı olduğunu, erkek eşlerın mastektomı hakkında konuşmaya karşı daha fazla olumsuz tepkı gosterdıklerı ve hem kadının, hem de erkeğın duygusal desteğe intıyaçları oiduğunu llerı surmuştur.

Meme kanserı tanısı konmuş, mastektomı yapılacak ve yapılmış olan hastaların ve alielerin psikososyal problemlerte başetmelerıne destek ve yardımın nasıl yurutulduğune baktığımızda hem bıreysel, hem de grup olarak psıkolojik destek ve terapı uygulamalasının yapıldığı dıkkat। çekmektedır

Baıder ve ark. (1984) tarafından, mastektomı olan 24 hastaya ameliyat sonrasında grupla psikolojk danışmanlık yapıımış ve bu danışma oturumlarında hastaların kaygı ve çokkunluk gıbı psıkolojkk sorunlarında onemlı bır azalma gorulmuştur

Welsman ve ark (Akt. Elb, 1991) Ise, grup terapısıne katılan kanser hastalarında kontrol grubundan daha az anksıyete gozlemışler, bırı psıkoterapı, dığerı eğıtımle gevşeme ağırlıklı ıkı farklı terapı yontemı arasında ise bır farklılık bulamamışlardır.

Bu konuda ulkemızde yapılan çalışmalar da yok denecek kadar azdır

Ure (1989), kanser hastalarınn benlık tasarımı, kaygı ve çokkunluk duzeyı, saldırganlık eğılımlerı ve bazı psıkolojık ozellıklerı uzerınde grupla psıkolojık danışmanın ve grup rehberlığı 
yardımlarının bır etkısı olup olmadığına bakmış, grup rehberlığı uygulaması sonrasında deneklerin somatızasyon ve benlık tasarımlarında olumlu yonde onemlı duzeyde değışmeler meydana gelmıştır Grupla psikolojik danışma ise etkilı bır yakłaşım olmamıştır Aynı şekılde kontrol grubu hastalarının problemlerinde de olumlu bır değışme gozlenmemıştır

\section{SONUÇ}

Amelyyat oncesi donem, iyı bır ameliyat sonrası donem yaşamak ıçın çok onemiıdır Amelıyat oncesı donemde hasta ve allesını bıl-

\section{KAYNAKLAR}

Adams F (1988) Neuropsychiatrıc Evaluation and Treatment of Delirum in Cancer Pattents Adv Pychosom Med, 182638

Barder ve ark (1984) Time Limited Thematic Group With Post-Mastectomy Patrents Journal of Psychosomatic Research 28(4) 233-330

Bazlı O Unal A (Ed) (1988) Cerrahı Ders Nottarı Ankara, Metay Yayıniar!

Bloom J $\mathrm{A}$ ve ark (1987) Psychological Response to Mastectomy A Journal of the American Cancer Soclety 59 (1) $189-195$

Cossileth BR, Sleinfeld AD (1987) Psychological Preperation of the Patient and Family A Journal Preperation of the Patient and Family of Ame. rican Cancer Society, $3(60)$ 547-552

Clifford E (1979) Psychological Effect of the Mastectomy M G Gerorgrade (Ed), Breast Reconstraction Following Mastectomy St Louls, The CU Mosby Comp

Dean C Hopwood P (1989) Llason Psychlatry in a Breast Cancer Unıt Britısh Journal Psychaatry, 155 98-100 glendırmenın ve psıkososyal desteğın kaygıyı azaittığı, hastanın uyumunu ve tedavıye katılımını kolaylaştırdığı çeşıtlı yayınlarda beIırtımektedır

Lıyezon psıkıyatrısı ıle onkolojı arasında yakın ışbırlığı, kanser hastalarının tedavı ve bakımı ıçın onemidır Konsultasyon-Lıyezon uygulamaiarında ekıp çalışması ve duzenlı ızlem, kanser hastalarının dınamıklerını anlamayı kolaylaştıracak ve bu hastaların psikososyal uyumlarma onemlı katkıda bulunacaktır

Derogatıs LR ve ark (1979) Psychologıcal Coping Mechanism and Survival Time in Metastatic Bre ast Cancer Jama, 242, (14) 1504-1508

Elbı H (1991) Kanser ve Psikıyatrı, Sorunlar Tans Sağaltım Turk Psıkıyatrı Dergııı, 2(2) 122-128

Fırat D, Çelık I (1998) Cancer Statıstıcs in Turkey and in the World (1993-1995) First Editon, AnkaraTurkey, Alp Ofset Matbaacilık Ltd Şı̀ , s 53-63

Hardman A Ve ark (1989) Effect of Psychiatric LIason Program on Consultation Rates and on Detection of Minor Psychiatric Disorders in Cancer Patlents American Journal Psychiatry, 146 898-901

Hopwood P G, Maquire G P (1988) Body image Problems in Cancer Patients The Britsh Journal of Psychatry, 2 (153) 47-50

Hutchinson A Ve ark (1979) Quality of Survivai of Patients Following Mastectomy Clinical Onkology, 5 (4) $391-392$

Massie M S, Holland J C (1988) Assesment and Management of the Cancer Patient with Depression Adv Psychosom Med, 18 1.12

Meyer L, Aspergen K (1989) Long Term Psychological Seguelue of Mastectomy and Breast Conserving Treatment for Breast Cancer Acta Oncologia, 28 (1) $13-18$ 
Northouse L L (1989) The Impact of Breast Cancer on Patıents and Husbands Cancer Nursing, 12(5) 276284

Ozkan S Turgay M (1995) Liyezon Psikiyatrisı Uygulama Modelı Içinde Meme Kansen Nedenıyle Cerrahı Gırışım Uygulanmış Hastalarda Psıkopatolojı ve Psıkolojık Uyumun Araştııııması Ozkan S (Ed), Konsultasyon-Lıyezon Psikiyatrısi, III Ulusal Konsuitasyon Liyezon Psikıyatı Kongresı ve Mezuniyet Sonrası Eğitım Kursu (1994-1995), Istanbul, s 301338

Ozturk MD (1978) Ruhsal Açıdan Kanser Kuçuksu MN (Ed), Klınık Onkolojı, Tuık Kanser Araşturna ve Savaş Kurumu Yayınları, Ankara, s 31-36

Polivy J (1975) Psychological Effects of Radical Mastectomy Public Health Reviews, 4 279-295
Schover LR (1991) The Impact of Breast Cancer on Sexuality, Body Image, and Intımate Relatıonships Cancer Journal Clınical 42(2) $112-20$

Ure O (1983) Mastektomı ve Psiko-Sosyal Uyum Acta Onkologla Turcsca, Ankara Onkolojı Hastanes! Bultenı, $16(1,2,3,4) 52-64$

Ure O (1989) Grupla Psıkolojk danışmanın ve Grup Rehberığının Kanserlı Hastaların Kaygıları Ben Iık Tasarımları ve Psıkolojık Rahatsızlıkları Uzerıne Et kısı Yayınlanmamış doktora Tezı A U Ankara

Wolberg W H ve ark (1989) Psychosexual Adaptation to Breast Cancer Surgery Cancer 63 (8) 1645 1655

Yalom ID (1995) Aşkın Celtadı ve Dığer PsIkoterapı Oykulerı Ing Çev Handan Saraç 1 Baskı Istanbul, Remzl Kitabevi, s 11-22 